\title{
Experimental Study of Diesel Engine Using Exhaust Gas Recirculation
}

\author{
Savan D. Patel ${ }^{1}$, Bhavesh D. Patel ${ }^{2}$, Kevin B. Patel ${ }^{3}$, Sagar A. Patel ${ }^{4}$, Mayank Sompura ${ }^{5}$ \\ ${ }^{1,2,3,4}$ Student of Mechanical Engineering, Valia Institute of Technology, Bharuch, Gujarat Technological University, India \\ ${ }^{5}$ Head of Mechanical engineering Department, Valia Institute of Technology, Bharuch, Gujarat Technological University, India
}

\begin{abstract}
Automobile emission is one of the major problem in environment. Engine emits the Carbon monoxide (CO), Hydrocarbon (HC), Nitrogen oxides $\left(\mathrm{NO}_{X}\right)$, and smoke density etc. in this the Nitrogen oxides $\left(\mathrm{NO}_{X}\right)$ emission leads to dangerous effects on environment. Therefore we will study on performance and emission characteristics of diesel engine and diesel fuel using exhaust gas recirculation with the help of EGR and control the Nitrogen oxides $\left(\mathrm{NO}_{X}\right)$ emission from diesel engine and also increase performance of diesel engine. For the better result, optimum condition of 15\% EGR is achieved. $20 \%$ bio fuel will reduce the NOx concentration by 25\%. A turbocharged internal combustion engine assembly with exhaust gas recirculation (EGR) includes an air compressor driven by an exhaust turbine, an EGR line that diverts Exhaust gases from an exhaust line leading from the engine to an air intake line leading to the engine from the compressor, and a combustion bypass line that conveys Compressed air from the compressor to the exhaust turbine without combustion. Diesel engines, a special type of internal combustion engine, use heat of compression, rather than electric spark, to ignite hydrocarbon fuels injected into the combustion chamber. Diesel engines have high thermal efficiency and thus, high fuel efficiency. They are widely used in commerce prompting continuous improvement in diesel engines and fuels. Concern for health effects from exposure to diesel exhaust arose in the mid-1900s and stimulated development of emissions regulations and research to improve the technology and characterize potential health hazards.
\end{abstract}

Keywords: Diesel engine, NOx, EGR, Brake thermal efficiency, Specific fuel consumption, heat recovery, emission

\section{Introduction}

In recent year due to globalization and industrial development, transportation industries are flourishing very fast. Such industries are very much responsible for atmospheric pollution whichis detrimental to human health and environment. Internal combustion engines are the main power source for the automobile vehicles which is used by transportation industries. Mostly all the diesel engines have high thermal efficiencies because of their high compression ratio and lean air-fuel operation.Major problem faced by today's world is environmental pollution of these vehicular traffic is a major contributor. Exhaust gases from vehicles includes $\mathrm{CO}, \mathrm{CO}_{2}, \mathrm{HC}, \mathrm{NO}_{\mathrm{X}}$ of these $\mathrm{NO}_{\mathrm{X}}$ is particularly very harmful. These are one of the chief constituents of smog, which have an adverse effect on ecological systems. They also contribute to the formation of acid rain. $\mathrm{NO}_{\mathrm{X}}$ also cause breathing illness in human beings. The development of a new generation of exhaust gas recirculation (EGR) valves and improvements in electronic controls allow a better EGR accuracy and shorter response time in transient condition. A present investigation is related to EGR (exhaust gas recirculation) for improve engine performance and efficiency. By this method the exhaust gas is used to recirculate in the engine and improve the performance and power of internal combustion engine.A number of strategies have been developed for alternative charge air handling and turbocharging to drive and control exhaust gas recirculation (EGR) to reduce emission in engine.One approach uses a single state variable geometry turbocharger (VGT), in combination With an EGR circuit to achieve the desired ratio of EGR rate and air/fuel ratio under transient and steady-state operation. In this arrangement, the EGR circuit generally includes a modulating (proportional) or on/off EGR valve, an EGR cooler, and an EGR rate measuring device with appropriate tubing or integral passages to direct exhaust gas to the engine intake under appropriate operating conditions. The management of EGR How is performed by an electronic control unit (ECU). The ECU may use closed loop control of the EGR flow which is dependent on EGR rate measurement. The ECU may also control the VGT and/or EGR valve based on input from the rate measurement device to regulate EGR flow. This leads to a lower (richer) air/fuel ratio in comparison to a non-EGR engine because the recirculated exhaust gas has less oxygen content than the charge air duet the oxygen being consumed during the previous combustion process.

\section{Details Description}

\subsection{Working Principle}

Pollutants are because of the incomplete burning of the airfuel mixture in the combustion chamber. The major pollutants emitted from the exhaust due to incomplete combustion are,

(a) Carbon monoxide (CO)

(b) Hydrocarbons (HC)

(c) Nitrogen oxides $\left(\mathrm{NO}_{\mathrm{X}}\right)$

If, combustion is complete, the only products being expelled from exhaust would be water vapour which is harmless, and carbon dioxide, which is an inert gas and, as such it is not directly harmful to humans.

\section{(a) Carbon Monoxide}

$\mathrm{CO}$ is a colorless, odorless, and tasteless gas that is slightly lighter than air. It is toxic to human and animals when encountered in higher concentration. CO is generally formed when the mixture is rich in fuel. The amount of $\mathrm{CO}$ formation increases as the mixture becomes more and richer in fuel. A small amount of CO will come out of the exhaust 


\section{International Journal of Science and Research (IJSR) \\ ISSN (Online): 2319-7064 \\ Index Copernicus Value (2013): 6.14 | Impact Factor (2015): 6.391}

even when the mixture is slightly lean in fuel because air fuel mixture is not homogenous and equilibrium is not established when the products pass to the exhaust. At the high temperature developed during the combustion, the products formed are unstable and following reactions take place before the equilibrium is established.

$2 \mathrm{C}+\mathrm{O}_{2}=2 \mathrm{CO}$

\section{(b) Hydrocarbon (HC)}

Hydrocarbons, derived from unburnt fuel emitted by exhausts, engine crankcase fumes and vapour escaping from the carburetor are also harmful to health. Hydrocarbons appears in exhaust gas due to local rich mixture pockets at much lower temperature than the combustion chamber and due to flame quenching near the metallic walls. A significant amount of this unburnt HC may burn during expansion and exhaust strokes if oxygen concentration and exhaust temperature is suitable for complete oxidation.

\section{(c) Nitrogen Oxides $\left(\mathrm{NO}_{\mathrm{X}}\right)$}

Oxides of nitrogen is produced in very small qualities can cause pollution. While prolonged exposure of oxides of nitrogen is dangerous to health. Oxides of nitrogen which occurs only in the engine exhaust are a combination of nitric oxide (NO) and nitrogen dioxide $\left(\mathrm{NO}_{2}\right)$. Nitrogen and oxygen react at relatively high temperature. $\mathrm{NO}_{\mathrm{X}}$ is formed inside the combustion chamber in post-flame combustion process in the high temperature region. The high peak combustion temperature and availability of oxygen are the main reasons for the formation of $\mathrm{NO}_{\mathrm{X}}$. In the present of oxygen inside the combustion chamber at high combustion temperature the following chemical reactions will take place behind the flame.

$$
\begin{aligned}
\mathrm{N}_{2}+\mathrm{O}_{2} & =2 \mathrm{NO} \\
\mathrm{N}_{2}+2 \mathrm{H}_{2} \mathrm{O} & =2 \mathrm{NO}+\mathrm{H}
\end{aligned}
$$

\subsection{System Components}

\section{(a) Diesel Engine}

The diesel engine is an internal combustion engine in which ignition of the fuel that has been injected into the combustion chamber is initiated by the high temperature which a gas achieves when greatly compressed.

\section{(b) Turbocharger}

A turbocharger is a turbine-driven forced induction device that increases an internal combustion engine's efficiency and power output by forcing extra air into the combustion chamber.

\section{(c) EGR Valve}

Most early EGR valves were vacuum-operated. A vacuum diaphragm opened and closed a valve, allowing and cutting off exhaust flow. An early refinement was a temperaturecontrolled shut-off in the vacuum source. This kept the EGR valve from opening when the engine was too cool.

\section{(d) Catalytic Convertor}

Catalytic converters are used in exhaust systems to provide a site for the oxidation and reduction of toxic by-products (like nitrogen oxides, carbon monoxide, and hydrocarbons) of fuel into less hazardous substances such as carbon dioxide, water vapor, and nitrogen gas. Catalyst material such as platinum and palladium are applied to a ceramic support which has been treated with an aluminum oxides wash coat.

\subsection{Schematic Diagram}

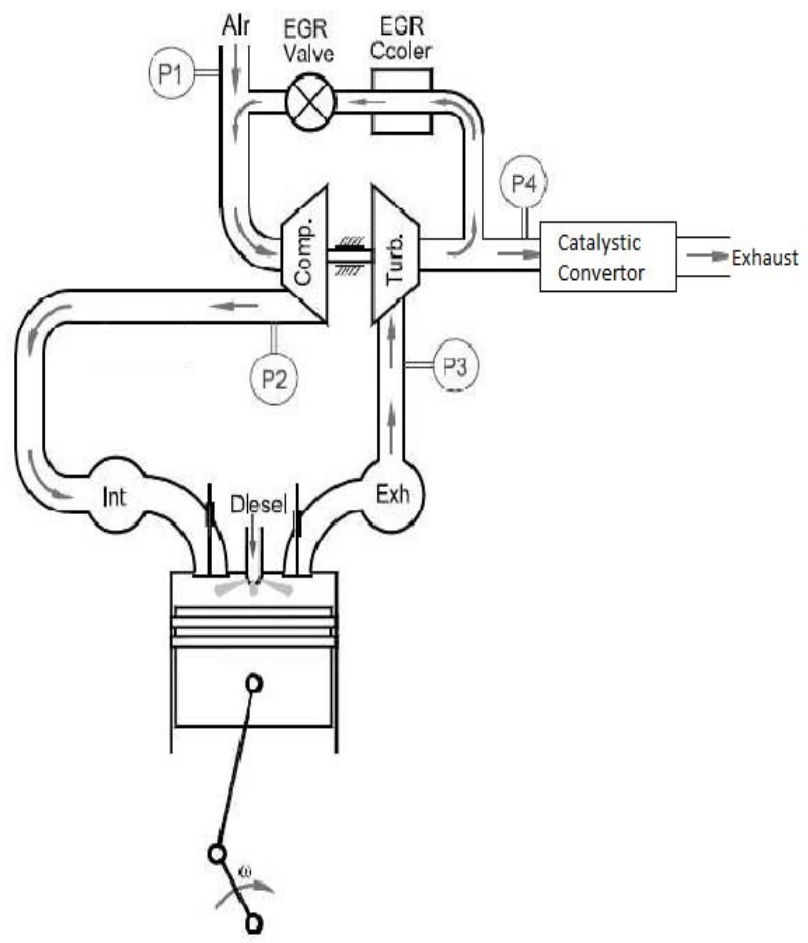

Figure 1: Schematic Diagram

Exhaust Gas Recirculation is an effective method of $\mathrm{NO}_{\mathrm{X}}$ control. The exhaust gases mainly consist of carbon dioxide, Nitrogen oxides etc. and the mixture has higher specific heat compared to atmospheric air. Recirculated exhaust gas displaces fresh air entering the combustion chamber with carbon dioxide and water vapour present in engine exhaust. As a consequence of this air displacement, lower amount of oxygen in the intake mixture is available for combustion. Reduced oxygen available for combustion lowers the effective air-fuel ratio. This effective reduction in air-fuel ratio affects exhaust emissions substantially. In addition to this, mixing of exhaust gases with intake air increases specific heat of intake mixture, which results in the intake air and reduced flame temperature, reduced rate of $\mathrm{NO}_{\mathrm{X}}$ formation reactions. When EGR system is applied, the engine intake consists of fresh air and recycled exhaust gas. Exhaust gases were tapped from exhaust pipe and connected to inlet airflow passage. An EGR control valve was provided in this pipe for EGR control. The exhaust gases were regulated by this valve and directly send to the inlet manifold, upstream of compressor or downstream of compressor. Sufficient distance for through mixing of fresh air and exhaust gases were ensured. The above shown system is also called as hot EGR because it not fitted with an EGR cooler which is used to cool the intake mixture.EGR involves replacement of oxygen and nitrogen of fresh air entering in the combustion chamber with the carbon dioxide and water vapour from the engine exhaust. The recirculation of part of exhaust gases into the engine intake air increases the specific heat capacity of the mixture and reduces the oxygen concentration of the intake mixture. These two factors combined lead to significant reduction in $\mathrm{NO}_{\mathrm{X}}$

\section{Volume 5 Issue 4, April 2016}




\section{International Journal of Science and Research (IJSR) \\ ISSN (Online): 2319-7064 \\ Index Copernicus Value (2013): 6.14 | Impact Factor (2015): 6.391}

emissions. EGR (\%) is defined as the mass percentage of the recirculated exhaust (MEGR) in total intake mixture.

$$
\% \mathrm{EGR}=\frac{\text { Mass of aur admitted without EGR }- \text { Mass of air admitted with EGR }}{\text { Mass of air admitted without EGR }}
$$

\subsection{Engine Specification}

Table 1: Engine specification

\begin{tabular}{|c|c|}
\hline Type & Four Stroke, Air-Cooled, Diesel \\
\hline Bore/Stroke, mm & $86 / 75$ \\
\hline Number of Cylinders & 1 ( One ) \\
\hline Displacement Ratio & 435 cc \\
\hline Compression Ratio & $19: 01$ \\
\hline Max Power & 7.5 HP @ 3600rpm \\
\hline Max Torque & 18 Nm @2400rpm \\
\hline Air Cleaner & Dry Type \\
\hline Oil Filter & Spin on \\
\hline Fuel filter & Paper Element Type \\
\hline Cooling System & Air Cooled \\
\hline Oil Sump Capacity & 1.4 liter \\
\hline
\end{tabular}

\section{Analysis of Working Model}

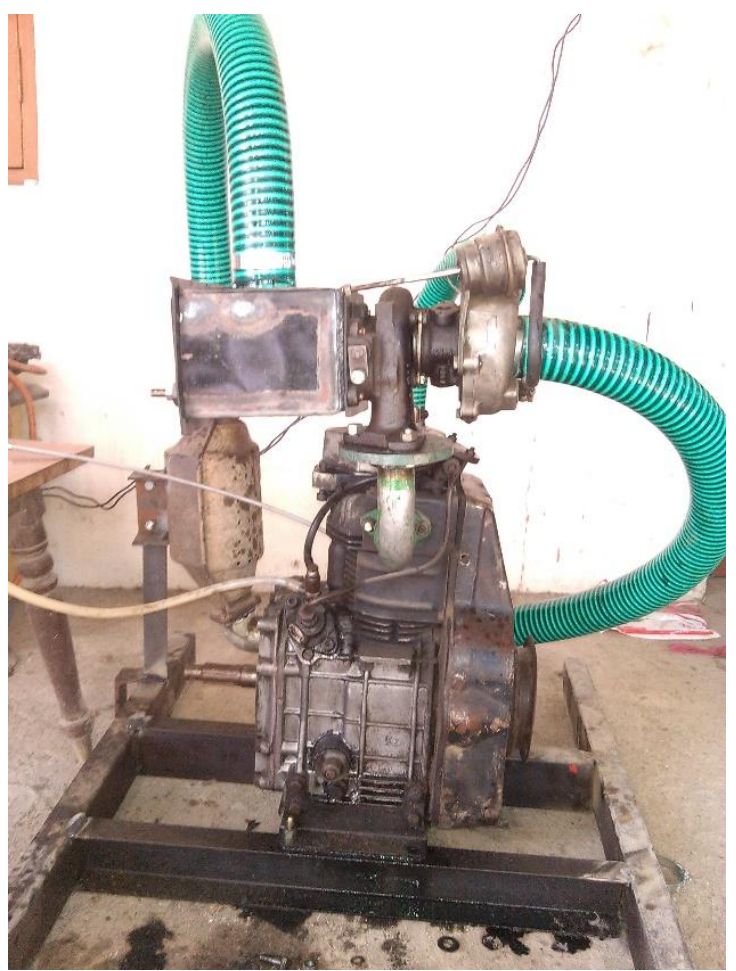

Figure 2: Working Model

The easier way to study the effects of single parameter variation while maintaining all others constant is to perform the test on a single cylinder engine with separate systems for the control of EGR rate, inlet temperature, air and fuel flows. By the way, this hides some limits of an actual engine: for instance, the boost pressure depends on energy available at the exhaust when using a turbocharger. The ultimate objective of our study being to propose in cylinder strategies to control $\mathrm{NOx}$ and $\mathrm{PM}$ emissions for future emissions standards, we have chosen to carry out the tests on a standard engine with limited modifications.

\subsection{Effect on EGR RATE}

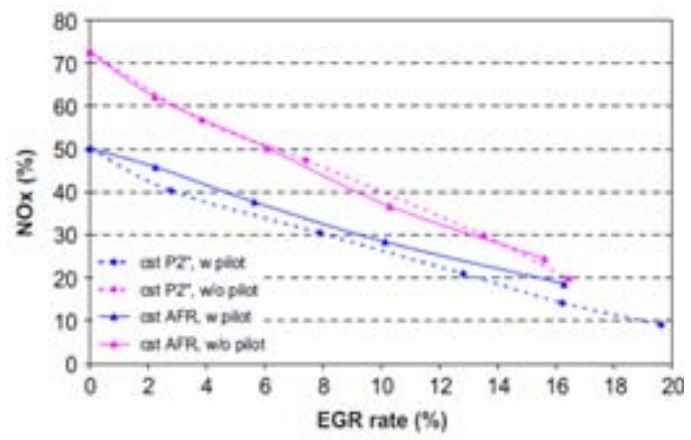

Figure 3

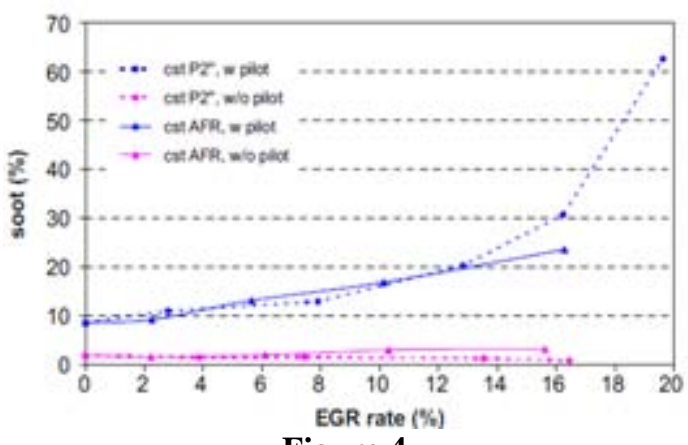

Figure 4

The influence of EGR on NOx and soot emissions is given in fig. The corresponding NOxsoot trade-offs are given infig. Firstly, for a given EGR rate, NOx emissions are higher and soot emissions lower without pilot injection for operating point no. 1 as for the influence of inlet temperature.

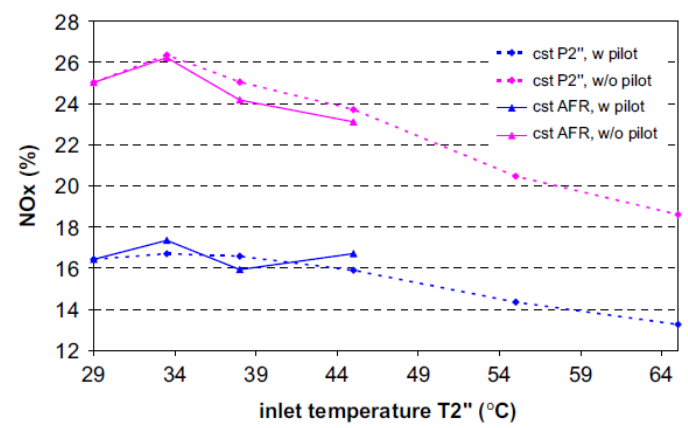

Figure 5

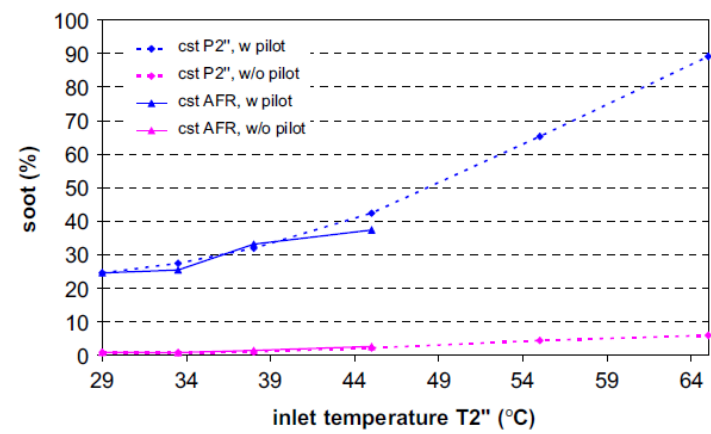

Figure 6 


\section{International Journal of Science and Research (IJSR) \\ ISSN (Online): 2319-7064 \\ Index Copernicus Value (2013): 6.14 | Impact Factor (2015): 6.391}

The corresponding influence on NOx and soot emissions for $0 \%$ and $15.5 \%$ EGR is given in figure respectively. First of all, it can be noticed that for a given inlet temperature T2"NOx emissions are higher and soot lower without pilot injection. Without pilot injection principal combustion is mainly premixed and the mean equivalence fuel-air ratio of the mixture formed during ID must be too low for soot inception, explaining why soot emissions seem to be very low in the case of premixed combustions on the engine tested. The corresponding ROHR is higher, resulting in higher local temperatures, thus promoting NOx formation, as explained by Musculus. Furthermore, for a given inlet temperature T2", NOx emissions are lower and soot emissions higher with 15.5\%EGR compared to 0\% EGR as traditionally observed.

\subsection{Benefits}

- It is most effective method to reduce the nitrous oxide emission from the engine exhaust.

- This method is very reliable in terms of fuel consumption.

- Harmless for the environment and human.

- Increase efficiency of diesel engine.

- Improve performance of engine.

- $\quad$ EGR is a very simple method. It has proven to be a very useful and it is being modified further to attain better standards.

\subsection{Conclusion}

Thus, as seen that using Exhaust Gas Recirculation Technique in engines, the emissions are very much controlled due to lesser amounts of $\mathrm{NO}_{\mathrm{X}}$ entering the atmosphere. Exhaust gases lower the oxygen concentration in combustion chamber and increase the specific heat of the intake air mixture, which results in lower flame temperatures. Thus the emission levels to be maintained are attained by the engines. It can be observed that 15\% EGR rate is found to be effective to reduce $\mathrm{NO}_{\mathrm{X}}$ emission substantially without deteriorating engine performance. As seen, Exhaust Gas Recirculation is a very simple method. It has proven to be very useful and it is being modified further to attain better standards. This method is very reliable in terms of fuel consumption and highly reliable. Thus EGR is the most effective method for reducing the nitrous oxide emissions from the engine exhaust. Many of the four wheeler manufacturers like Ford Company, Benz Motors etc. used this technique to improve the engine performance and reduce the amount of pollutants in the exhaust of the engine.

\section{References}

[1] A. Mohebbi, S. Jafarmadar and J. Pashae, "Performance Evaluation and Emissions improving of Turbocharged DI Diesel Engine with Exhaust Gas Recirculation (EGR)" International Journal of Automotive Engineering. Vol. 2, Number 2, April 2012

[2] A.Paykani, A. Akbarzadeh and M.T.ShervaniTabar, "Experimental Investigation of the Effect of Exhaust Gas Recirculation on Performance and Emissions
Characteristics of a Diesel Engine Fueled with Biodiesel". IACSIT International Journal of Engineering and Technology, Vol.3, No.3, June 2011

[3] Deepak Agarwal , Shrawan Kumar Singh , Avinash Kumar Agarwal: Effect of Exhaust Gas Recirculation (EGR) on performance, emissions, deposits and durability of a constant speed compression ignition engine(2011)3-7

[4] DonepudiJagadish, Dr.Puli Ravi Kumar, Dr.K.Madhu Murthy, "PERFORMANCE CHARACTERISTICS OF A DIESEL ENGINE OPERATED ON BIODIESEL WITH EXHAUST GAS RECIRCULATION" International Journal of Advanced Engineering Technology E-ISSN 0976-3945

[5] Jaffar Hussain, K. Palaniradja, N. Alagumurthi, R. Manimaran. "Effect of Exhaust Gas Recirculation (EGR) on Performance and Emission characteristics of a Three Cylinder Direct Injection Compression Ignition Engine". Alexandria Engineering Journal (2012) 51, 241-247

[6] M. Gomaa, A.J. Alimin, K.A. Kamarudin: The effect of EGR rates on NOX and smoke emissions of an IDI diesel engine fuelled with Jatropha biodiesel blends(2011)3-4

[7] Ming Zheng , Graham T. Reader , J. Gary Hawley : Diesel engine exhaust gas recirculation - a review on advanced and novel concepts(2004)3-5

[8] SAE Paper2003-01-1068, Timothy Jacobs, Dennis Assanis and Zoran Filipi, "The Impact of Exhaust Gas Recirculation on Performance and Emissions of a heavy duty Diesel Engines"., Automotive Research Center, The University of Michigan.

[9] Zheng M, Reader GT. "An experimental analysis of EGR on operational stabilities of Diesel engines". ASME ICE, vol. 36-1, 1993. p. 101-106B.

[10]Zheng M, Reader GT. "An experimental analysis of EGR on operational stabilities of Diesel engines". ASME ICE, vol. 36-1, 2001. 